\title{
Kurikulum PAUD, Gamelan, dan Wayang Orang: Refleksi Kebermaknaan Jurusan PAUD bagi Masyarakat Bejiharjo, Karangmojo, Gunungkidul
}

\author{
Joko Pamungkas, Amir Syamsudin, Ika Budi Maryatun \\ Program Studi PG PAUD, Fakultas Ilmu Pendidikan, Universitas Negeri Yogyakarta \\ Jalan Colombo No. 1 Yogyakarta, Indonesia \\ E-mail: joko_pamungkas@uny.ac.id
}

\begin{tabular}{ll}
\hline \hline ARTICLE INFO & ABSTRACT \\
\hline \hline Article history: & Kegiatan Pengabdian kepada Masyarakat (PPM) ini terdapat tiga seri workshop \\
Received: $9-12-2019$ & yang diselenggarakan, yaitu workshop bedah kurikulum PAUD dan pembelajaran \\
Revised: $16-12-2019$ & saintifik; workshop seni gamelan dan karawitan; dan workshop pementasan seni \\
Accepted: $23-12-2019$ & wayang orang. Subjek sasaran PPM adalah guru-guru PAUD, dan remaja karang \\
& taruna di Sokoliman, Bejiharjo, Karangmojo, Gunungkidul. Keterampilan guru \\
Keywords: & dalam bermain gamelan masih kurang karena belum ada pelatihan karawitan dan \\
Kurikulum PAUD, gamelan, & gamelan. Setelah dilakukan workshop gamelan dan karawitan, dapat dilihat \\
karawitan, wayang uwong, & bahwa Guru-guru PAUD di Gugus VI Karangmojo memiliki potensi untuk \\
guru PAUD & melestarikan karawitan. Pementasan wayang uwong bertujuan untuk memberikan \\
& kegiatan kepada karang taruna berbasis budaya, serta menjalin kerjasama antara \\
& karang taruna Sokoliman dengan Universitas Negeri Yogyakarta.
\end{tabular}

There are three series of workshops held in community service activities, namely early childhood curriculum analysis and scientific learning; gamelan and musical training; and training on wayang uwong performance. The target subjects of PPM are PAUD teachers, and youth groups in Sokoliman, Bejiharjo, Karangmojo, Gunungkidul. Teacher skills in playing gamelan are still lacking because there is no musical training and gamelan. After a gamelan and musical workshop, it can be seen that PAUD teachers in Karangmojo Cluster VI have the potential to preserve musical instruments. The wayang uwong staging aims to provide activities to culture-based youth organizations, as well as to establish cooperation between Sokoliman youth organizations and Yogyakarta State University.

\section{PENDAHULUAN}

Hasil wawancara informal dengan guru-guru TK yang menjadi peserta PPG 2018 yang dikukuhkan dengan pengamatan terhadap proses pembelajaran anak usia dini di Taman kanak-kanak yang menjadi tempat PPL ditemukan fakta bahwa penguasaan kurikulum 2013 belum begitu jelas dan nama instrument evaluasi pembelajaran AUD hanya dituliskan di Rencana Pelaksanaan Pembelajaran Harian (RPPH), namun tidak didukung dengan instrumen evaluasi pembelajaran AUD yang sesungguhnya. Fakta ini menunjukkan ada kesenjangan antara teori pembelajaran dengan praktik pembelajaran. Secara teoritis, kemasan pembelajaran meliputi penyusunan RPPH, penyiapan atau pembuatan media pembelajaran, dan pembuatan instrument evaluasi pembelajaran. Hanya ada dua komponen pembelajaran yang disiapkan, sementara komponen evaluasi tidak direncanakan. Persoalannya adalah mengapa kesenjangan ini terjadi. Boleh jadi guru TK mengikuti "kebiasaan umum" evaluasi pembelajaran, yaitu setelah pembelajaran selesai, para guru mulai mengevaluasi hasil karya anak, seperti gambar, coretan, hasil kerja atau sejenisnya. Sementara proses bagaimana anak tersebut menggambar, mencoret, atau membuat suatu karya tidak terekam dengan baik. Boleh jadi juga guru TK tahu tentang bagaimana seharusnya melakukan evaluasi, tetapi tidak ada contoh bagaimana melakukannya.Bahkan boleh jadi juga guru TK tidak tahu bagaimana melakukan evaluasi pembelajaran AUD menurut standar normative.

Berbanding terbalik dengan fakta di atas, mahasiswa PG-PAUD begitu jelas dengan kurikulum 2013 serta dapat membuat 12 jenis instrumen evaluasi pembelajaran AUD yang terdiri 9 instrumen 
pengumpul data perkembangan anak dan 3 instrumen analisis data perkembangan anak selama dalam satu semester. Namun ke-12 instrumen tersebut belum diujicobakan penggunaannya di Taman kanakkanak. Oleh karena itu, karya-karya mahasiswa tersebut perlu di ujico bakan di taman kanak-kanak mitra KKN-PPL untuk melihat kelayakan penggunaan instrumen tersebut dan kemudahan dalam penggunaannya. Dengan demikian, perlu melakukan pengabdian implementasi penggunaan instrumen evaluasi pembelajaran AUD.

Penelitian pengabdian masyarakat (PPM) yang diselenggarakan di Kabupaten Gunungkidul ini dimaksudkan sebagai pengabdian dari akademisi kepada masyarakat lewat suatu lembaga Pendidikan yang bergerak di bidang Pendidikan anak usia dini, dalam hal ini dibawah naungan Universitas Negeri Yogyakarta (UNY) yang diadakan oleh Dosen PGPAUD UNY.Pengabdian pada masyarakat ini diadakan di Sokoliman, Bejiharjo, Karangmojo Kabupaten Gunungkidul sebagai suatu pengabdian dan penelitian di daerah yang memiliki potensi besar dalam bidang pendidikan untuk dikembangkan terutama pada Pendidik anak usia dini. Penelitian pengabdian masyarakat (PPM) ini melibatkan berbagai kalangan termasuk didalamnya adalah dosen-dosen PGPAUD UNY yang telah bersedia untuk memberikan materi-materi yang bermasyarakat dan termasuk dalam pengabdian ilmu serta perbaikan kualitas sumber daya manusia di bidang pendidikan.

Pelaksanaan kegiatan ini dilaksanakan di Sokoliman, Bejiharjo, Karangmojo, Gunungkidul dilatarbelakangi karena pelaksanaan kurikulum dan pelatihan tentang kurikulum yang belum difasilitasi secara menyeluruh dan kontinu oleh pemerintah daerah sekitar, pembelajaran berbasis saintifik yang belum banyak dilaksankaan di daerah tersebut. Pelestarian budaya perlu dilaksanakan sejak usia dini. Berdasarkan hasil penyebaran angket di Gunung Kidul khususnya di gugus PAUD VI Karangmojo, bahwa pemberian materi tentang kearifan lokal kepada anak sudah diberikan oleh sebagian besar Taman Kanak-kanak. Guru sudah mengenalkan kepada anak tentang permainan tradisional, alat masak tradisional, dan upacara adat. Namun pengenalan tentang gamelan dan karawitan belum pernah disampaikan di sekolah sebagai bahan ajar. Hal itu disebabkan oleh kurangnya keterampilan guru dalam bermain gamelan dan tidak ada dana yang mencukupi untuk mendorong pelaksanaan pembelajaran karawitan. Pementasan wayang uwong karang taruna Sokoliman diadakan lantaran melihat kekompakan anggota karang taruna Sokoliman yang begitu erat. Dari situ munculah ide untuk memberikan kegiatan yang beda dari yang lain yaitu kegiatan berbasis budaya, pelatihan dan pementasan wayang uwong.

\section{METODE}

Kegiatan pengabdian pada masyarakat ini meliputi workshop pengembangan kurikulum PAUD dan instrumen evaluasi, pendampingan uji coba penggunaan di lembaga PAUD, workshop gamelan bagi anak-anak dan remaja, workshop pementasan wayang orang. Pengabdian pengembangan kurikulum PAUD dan pendampingan penggunaan instrumen assesmen pembelajaran di Taman KanakKanak Se-Kecamatan Karangmojo Gunungkidul dilaksanakan pada bulan April - Agustus 2019. Pengabdian dilaksanakan di pendopo Sokoliman dengan melibatkan guru Taman Kanak-kanak seKecamatan Karangmojo Gunungkidul. Sebagai salah satu bentuk pengabdian dari kalangan akademisi kepada masyarakat dalam naungan lembaga Pendidikan, maka diadakakan Penelitian dan pengabdian masyarakat (PPM).

PPM ini berbetuk pelatihan kepada para guru pendidikan anak usia dini dan peningkatan sumber daya manusia di bidang pendidikan sebagai bentuk pengabdian dari suatu lembaga Pendidikan kepada Masyarakat yang akan dijabarkan sebagai berikut: diberikannya fasilitas Workshop kepada para pendidik, pendidikan anak usia dini di Kabupaten gunungkidul berupa pelatihan tentang Kurikulum PAUD dan Pembelajaran berbasis saintifik. Penyediaan fasilitas berupa pembibcara yang didatangkan langsung dari dosen pendidikan anak usia dini, FIP UNY.

\section{HASIL DAN PEMBAHASAN}

\section{Hasil}

Hasil pengabdian pada masyarakat oleh jurusan PAUD meliputi pengembangan kurikulum PAUD dan instrumen evaluasinya, pelatihan gamelan, dan pelatihan wayang orang.

\section{Workshop Kurikulum PAUD}


Pelaksanaan pembelajaran berbasis saintifik pada anak usia dini merupakan hal yang sangat penting. Hal ini dapat mengembangkan berbagai aspek perkembangan anak. Lebih baik dikenalkan pada anak sejak lahir atau sebelum memasuki sekolah. Pengalaman anak mengumpulkan dan mengolah informasi adalah fondasi anak belajar berpikir saintifik, kemampuan anak mengembangkan berpikir saintifik dapat distimulus sejak usia dini, apabila anak mengembangkan berpikir saintifik dapat memahami sebuah permasalahan dan berpikir mencari jalan untuk menyelesaikan permasalahan, implementasi pendekatan saintifik pada pendidikan anak usia dini adalah suatu proses awal agar anak memiliki pengetahuan tentang saintifik dengan mengenal lingkungan sekitarnya, memiliki wawasan kognitif untuk menyelesaikan masalah di sekitarnya dan lain-lain. Dalam proses saintifik memeiliki beberapa tahapan pembelajaran berupa mengamati (observing), menanya (Questioning), mencoba/mengumpulkan (Trying/ Collecting), Menalar/ menegosiasi (Associating), Mengkomunikasikan (Communicating) (Erni Munastiwi, 2015, Vol 1).

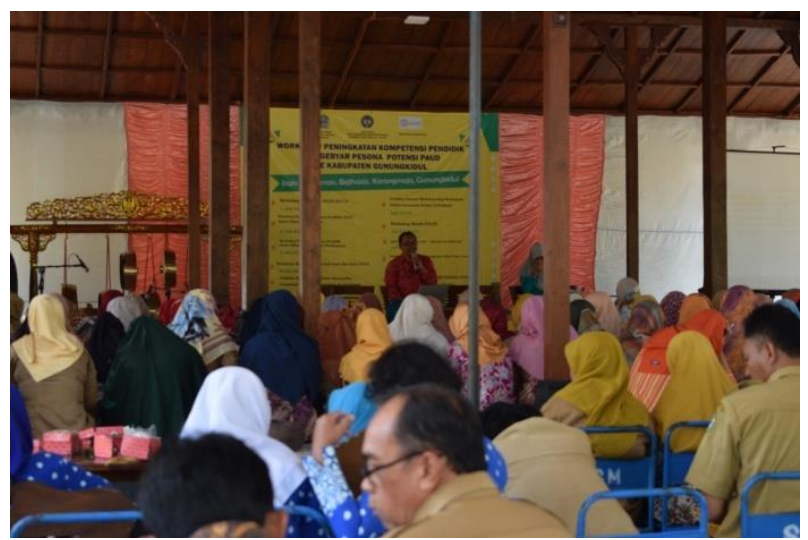

Gambar 1. Penyampaian materi tentang kurikulum paud oleh Amir Syamsyudin

Acara ini dilaksanakan pada hari Senin, 1 Juli 2019 di Pendopo Sokoliman, Bejiharjo Karangmojo Kabupaten Gunungkidul. Dengan diikuti oleh lebih dari 100 peserta dari berbagai TK di kabupaten Gunungkidul, acara ini merupakan serangkaian acara dari Penelitian dan Pengabdian Masyarakat (PPM), Kegiatan yang dilaksanakan di Pendopo Sokoliman ini awalnya di konsep sebagai workshop, dan ada hasil karya yang dihasilkan setelah penyampaian materi selesai, namun pada berjalannya sesi penyampaian materi kegiatan ini sedikit mengalami perubahan, bahwa setelah penyampaian materi selesai oleh Dr. Amir Syamsyudin, M.Pd. dan ibu Ika Budi Maryatun tidak dihasilkan pada hari itu juga, bamun dikirimkan ke E-mail sebagai hasil karya dari peserta yang mengikuti workshop tersebut.

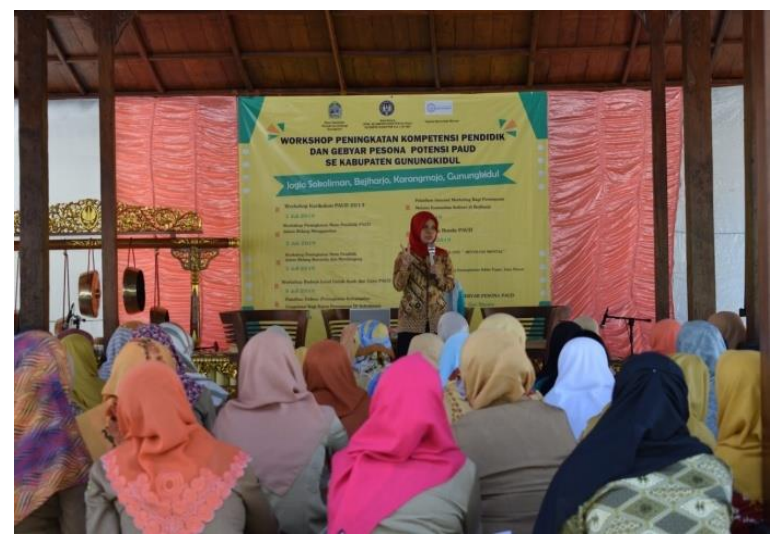

Gambar 2. Penyampaian Materi tentang pembelajaran Saintifik oleh Ika Budi Maryatun

Evaluasi kegiatan ini adalah jarak tinggal beberapa peserta guru TK di Kabupaten Gunungkidul yang cukup jauh, jadi beberapa ada yang terlambat untuk datang. Selain itu dalam pelaksanaannya yang sebelumnya harusnya ada workshop latihan secara langsung di tempat setelah penyampaian materi dan tanya jawab, pada saat tersebut tidak dilaksanakan karena waktu yang dialokasikan untuk 
kegiatan tersebut disesuaikan dengan para peserta yang memiliki jarak rumah yang jauh, dan akhirnya diberikan solusi bahwa hasil workshop dikirimkan ke email kedua pemateri. Faktor pendukung kegiatan adalah pertama, tempat penyelenggaraan kegiatan yang dilakukan di Pendopo dan berkonsep sarasehan lebih memudahkan peserta dan pembicara selama kegiatan penyampaian materi berlangsung. Kedua, dukungan dan antusias dari para peserta yang terdiri dari para Pendidik Taman Kanak-Kanak di Kabupaten Gunungkidul, dan ketiga materi yang disampaikan langsung oleh para dosen jurusan Pendidikan Anak Usia dini. Faktor penghambat meliputi waktu yang dialokasikan untuk penyampaian materi ternyata kurang untuk melanjutkan praktek yang akhirnya dikirim ke email pemateri, serta lokasi sekolah dan domisili peserta yang tidak sama dan sebagian memiliki domisili di kecamatan yang jauh, jadi diperlukan estimasi waktu yang pasti agar tidak banyak kegiatan terbuang percuma.

\section{Workshop Gamelan}

Dilihat dari potensi dan semangat Guru-guru PAUD gugus VI Karangmojo. Sehingga dari Dosen PGPAUD UNY memberikan kesempatan kepada Guru untuk berlatih Karawitan dengan menggunkan Gamelan milik kampus. Budaya di Indonesia sangat beragam. Oleh sebaba itu perlu dilestarikan oleh semua warga. Di Jawa terdapat salah satu budaya musik tradisional yaitu musik gamelan. Menurut Hartono, Gamelan Jawa adalah seperangkat alat musik yang menjadi salah satu objek penting dalam lingkup pembicaraan musik di dunia.

Gamelan Jawa terdiri dari kurang lebih dua puluh jenis instrumen. Secara keseluruhan gamelan Jawa memiliki kurang tujuh puluh lima buah, tergantung pada kebutuhan dengan rincian bahwa setiap instrumen terdiri dari dua buah untuk masingmasing laras (Lindsay, 1979: 3). Gamelan terdiri dari Seperangkat Gamelan Slendro dan Pelog

Workshop Pengenalan Gamelan dilaksanakan pada Hari Jumat 19 Juli 2019 dimulai pada pukul 08.00 WIB. Kegiatan pertama diawali dengan pembukaan oleh Bapak Joko Pamungkas, M.Pd yang mana sekaligus sebagai pembicara. Kegiatan selanjutnya yaitu workshop gamelan yang dipandu oleh Pengrawit Kinanthi Nastiti PG PAUD UNY. Kegiatan gamelan diawali dengan pengenalan namanama gamelan yang ada. Seperti kendhang, gong, kempul, bonang, saron, demung dan lain-lain. Selanjutnya dialanjutkan dengan pengenalan instrumen gamelan. Pada pelatihan kali ini, lagu yang diberikan adalah Suwe Ora Jamu.

Antusias guru saat mengikuti workshop samgat tinggi. Guru-guru sangat bersemangat dalam mengikuti kegiatan ini. Walaupun ini merupakan pengalaman pertama, namun ketika dilakukan praktek bermain karawitan, guru sudah bisa memainkan dengan bagus. Meskipun masih perlu bimbingan dari mahasiswa dalam membaca notasi.

Kegiatan ini diakhiri dengan guru bermain gamelan dengan tanpa bantuan daru mahasiswa. Untuk percobaan pertama, hasilnya sudah bagus walaupun belum bisa "suwuk" atau memberhentikan lagu.

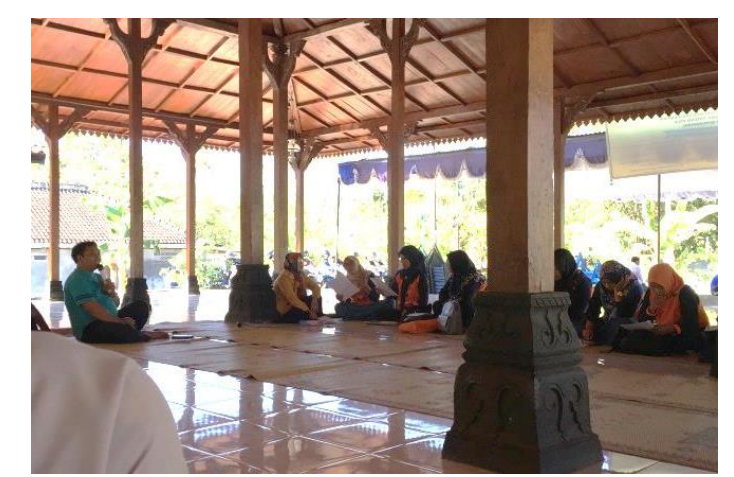

Gambar 3. Workshop karawitan saat metode ceramah

Berdasarkan hasil pelaksanaan dapat dilihat bahwa ada potensi yang dimiliki pendidik PAUD di Gugus VI Karangmojo untuk melestarikan budaya karawitan. Akan lebih bagus bila potensi tersebut dilatih dan dikembangkan secara terus menerus. Evaluasi dari kegiatan tersebut adalah tidak semua peserta dapat memukul gamelan secara bersama-sama. Terdapat tiga peserta yang bermain gamelan dengan bergantian. Sehingga perlu ada tambahan gamelan agar semua peserta dapat bermain secara 
bersama-sama. Kemudian untuk durasi yang diberikan kurang lama karena kegiatan tersebut dilaksanakan pada hari jumat. Peserta cukup sulit untuk dikondisikan, karena keingintahuannya tinggi dan ingin mencoba semua gendhing yang ada.

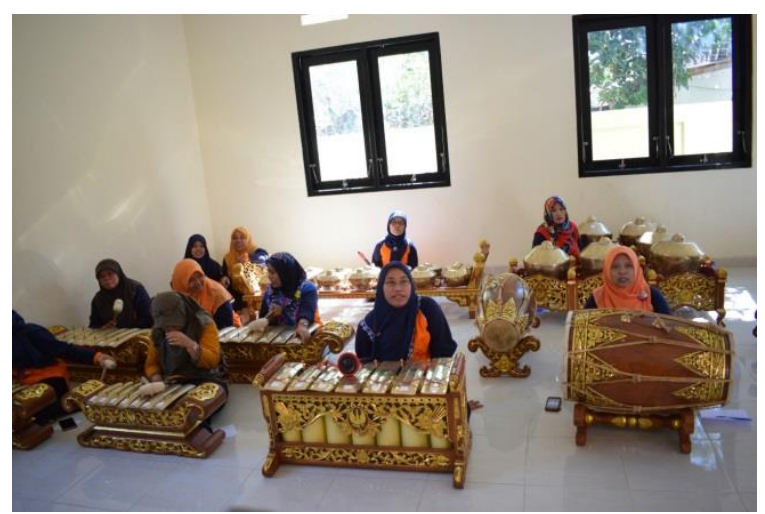

Gambar 4. Karawitan mandiri tanpa pendampingan

Selain itu juga karena workshop yang dilakukan dapat berjalan dengan lancar karena ada banyak pihak yang terkait. Yaitu dukungan sarana dan prasarana dari Rektor Universitas Negeri Yogyakarta, Kerjasama yang baik antar PGPAUD UNY dengan Gugus VI PAUD, serta kerjasama UNY dengan Dinas Pendidikan, Kebudayaan dan Olahraga Gunung Kidul dan Kerjasama UNY dengan Pemuda Sokoliman.

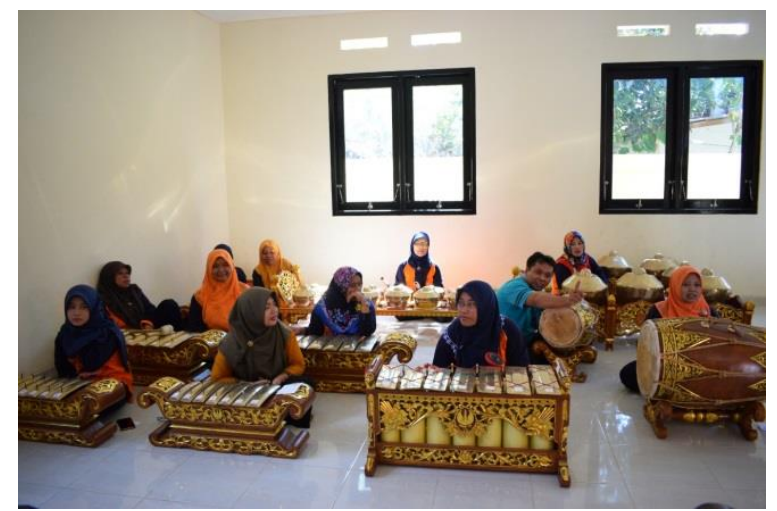

Gambar 5. Karawitan dengan didampingi dosen

Pelaksanaan workshop ini dapat terlaksana dengan baik karena sesuai dengan kondisi yang ada berdasarkan survey bahwa perlu adanya pelatihan tentang karawitan. Sehingga peserta workshop senang dengan kegiatan ini karena merasa membutuhkannya. Hambatan yang ada pada kegiatan ini adalah terbatasnya gamelan yang di sediakan oleh UNY. Walaupun demkian, peserta tetap menikmati acara dan kegiatan dapat terlaksana sesuai dengan rencana.

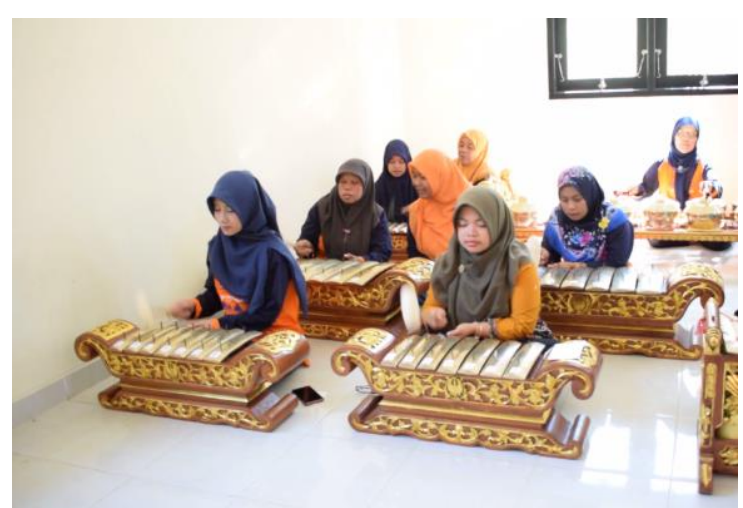

Gambar 6. Workshop karawitan metode praktek 


\section{Pelatihan Wayang Orang}

Wayang adalah salah satu budaya jawa yang dipegang teguh telah menciptakan sikap, kepribadian dan gaya serta perilaku orang jawa menjadi sosok yang simpatik, halus, santun, toleran, fleksibel dan menyukai keharmonisan. Wayang memiliki 3 aspek penting (tontonan, tatanan, tuntunan) yang dapat digunakan sebagai media apresiasi budaya Jawa terhadap remaja, khususnya di perkotaan. Manfaat hasil dari kegiatan wayang adalah sebuah media kampanye cinta budaya diseluruh daerah Indonesia, yang dimana masing-masing daerah memiliki nilai warisan tinggi, dengan demikian masyarakat Indonesia dapat membangun negara menjadi lebih baik, karena budaya yang beragam merupakan identitas bangsa Indonesia.

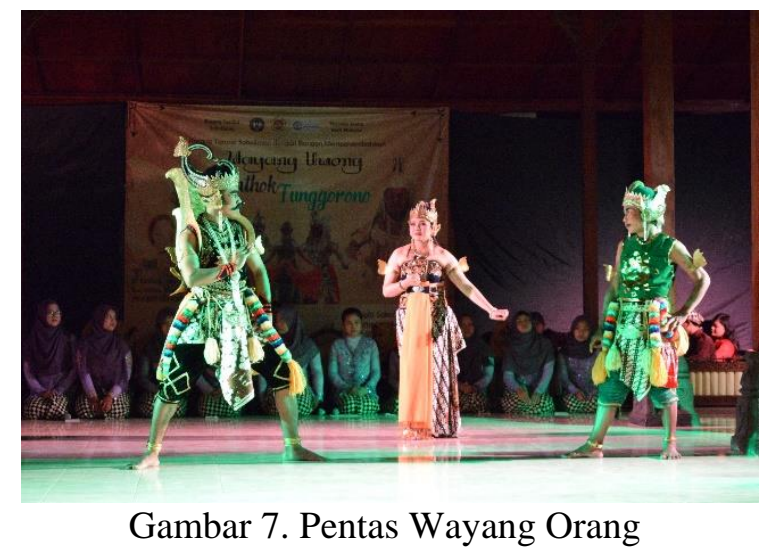

Kegiatan pementasan wayang uwong pathok tunggorono bertujuan untuk memberikan kegiatan kepada karang taruna berbasis budaya, serta menjalin kerjasama antara karang taruna Sokoliman dengan Universitas Negeri Yogyakarta. Kegiatan wayang uwong karang taruna memberikan manfaat bagi karang taruna Sokoliman, lembaga dan mahasiswa Universitas Negeri Yogyakarta serta warga Sokoliman setempat dari segi keilmuan budaya, sosial, ekonomi, dan Pendidikan.

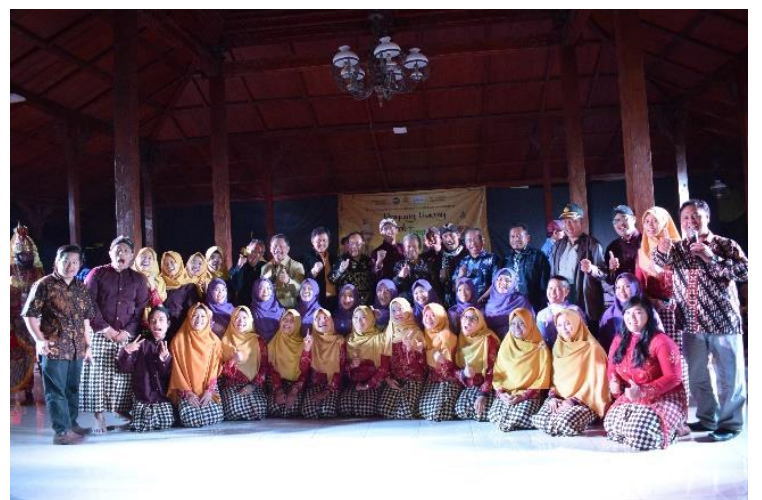

Gambar 8. Pengrawit, sinden, dosen, dan Rektor UNY

Karang taruna Sokoliman melakukan latihan wayang uwong yang dilanjutkan pementasan di Joglo Sokoliman pada hari jumat tanggal 9 Agustus 2019 pukul 19.30 Wib. Dengan dihadiri oleh Rektor Universitas Negeri Yogyakarta, LPPM UNY, Dekan dan wakil dekan 1 dan 2 FIP UNY, Kepala jurusan PLS, Dosen PLS, wakil bupati Gunung Kidul, bunda Paud Gunung Kidul, serta warga sekitar. Pementasan wayang uwong Pathok Tunggorono berlangsung dengan lancar tanpa kendala dan para penonton merasa terhibur dengan adanya pementasan wayang uwong tersebut. Dalam pementasan wayang uwong disutradarai oleh bapak Joko Pamungkas M.Pd, selain melibatkan pemuda Sokoliman sendiri juga melibatkan mahasiswa tim karawitan Kinanthi Nastiti Pg Paud UNY sebagai tim pengiring musik untuk wayang uwong dibantu oleh penata iringan Gondhol Sumargiono.

Sasaran yang ingin dituju oleh karangtaruna Sokoliman Gunungkidul dan UNY, yaitu perhatian dari masyarakat luas, terutama pada pemerintah desa setempat, tokoh masyarakat, dan para sesepuh 
atau orang tua untuk selalu menjaga dan melestarikan kebudayaan jawa, terutama pada sendra tari wayang orang. Oleh karena itu, karangtaruna Sokoliman Gunungkidul bekerjasama dengan UNY untuk dapat menarik perhatian masyarakat sekitar dan khalayak ramai untuk terus mencintai dan melestarikan kebudayaan Jawa dengan cara pentas wayang orang yang disiarkan langsung oleh website resmi UNY dan liputan dari beberapa media massa.

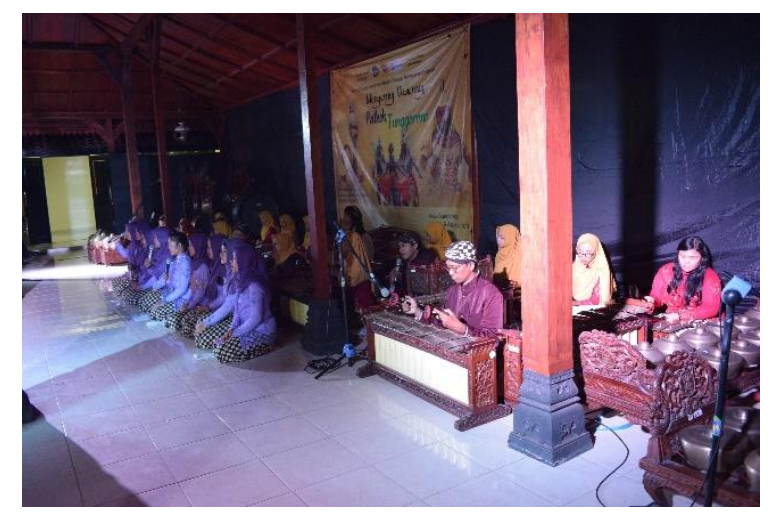

Gambar 9. Pengrawit dan Sinden

Dengan beberapa hal di atas, diharapkan dapat menjadikan masyarakat ramai lebih peduli dan memperhatikan kebudayaan kita, serta sadar bahwa Indonesia juga kaya akan budaya. Pada event ini, Wakil Bupati Kabupaten Gunungkidul juga diundang untuk menyaksikan pementaan wayang orang yang berjudul Pathok Tunggorrono ini. Metode yang digunakan dalam pementasan pathok tunggorono ini adalah metode ceramah ketika memberikan materi kemudian dipraktekkan secara berulang-ulang. Setelah dipraktekkan kemudian ditampilkan dan dikemas dalam sebuah pementasan.

Kegiatan wayang orang ini dipentaskan di Joglo Sokoliman pada tanggal 9 Agustus 2019 pada pukul 19.30 WIB. Dimulai dari persiapan tempat pada pagi hari yaitu pemasangan tenda beserta layout kursi. Dilanjutkan dengan persiapan pentas para penari dan tokoh. Rias dilakukan pada pukul 15.00 hingga pada pukul 19.30. Pathok Tunggorono ini diperankan oleh karang taruna Sokoliman dengan sekitar 46 orang. Pentas ini diiringi oleh Tim Karawitan Kinanthi Nastiti PG PAUD FIP UNY. Karangtaruna Sokoliman berhasil menampilkan secara apik pementasan ini dengan disaksikan oleh wakil bupati, Rektor UNY dan juga warga sekitar Sokoliman.

Evaluasi yang pertama yaitu pada bagian dokumentasi. Pada bagian dokumentasi perlu ada seseorang yang memang khusus untuk dokumentasi sja. Sehingga ketika proses dan pentas semua ada rekam jejaknya. Faktor pendukung kegiatan adalah pelatih yang senantiasa memberikan ilmu dan arahan kepada para pemain wayang uwong; Semangat pemuda karang taruna yang membara; Kerjasama yang baik antara UNY denga karang taruna dan warga sekitar Sokoliman; Mendapatkan berbagai dukungan dari berbagai pihak dalam bentuk sponsor; Tim karawitan Kinanthi Nastiti yang tidak pernah letih berlatih untuk mengiringi pementasan wayang uwong Pathok Tunggorono. Faktor penghambat kegiatan dalah penyatuan waktu antara pemain, pelatih dan tim karawitan; Waktu tempuh menuju sokoliman lama; Jarak Jogja dan Sokoliman Gunungkidul jauh; Latihan atau tempuk gendhing antara pemain wayang dan tim karawitan terlalu sedikit.

\section{SIMPULAN}

Pendidikan Anak Usia dini meliputi banyak aspek yang harus dikembangkan oleh para pendidik serta lembaga Pendidikan yang terkait, diantara banyak yang harus dikembangkan salah satunya adalah kurikulum PAUD yang harus dipahami dan diimplementasikan secara menyeluruh dan dalam satu kesatuan, selain itu jika seorang pendidik sudah dibekali tentang bagaimana cara implementasi langsung maka pada saat pembelajaran di kelas dapat dengan mudah untuk mengajarkan kepada peserta didik. Dalam kegiatan ini terdapat dua workshop yang diadakan yakni Workshop bedah kurikulum PAUD dan pembelajaran Saintifik yang keduanya dilatihkan kepada guru-guru di kabupaten Gunungkidul yang diharapkan dapat menjadi bekal untuk para pendidik untuk dapat mengimplementasikan secara langsung pada anak di TK tersebut.

Kegiatan workshop dibuat berdasarkan hasil survey, bahwa pengenalan tentang gamelan dan karawitan belum pernah disampaikan di sekolah sebagai bahan ajar. Hal itu disebabkan oleh 
kurangnya keterampilan guru dalam bermain gamelan dan tidak ada dana yang mencukupi untuk mendorong pelaksanaan pembelajaran karawitan. Setelah dilakukan workshop karawitan, dapat dilihat bahwa Guru-guru PAUD di Gugus VI Karangmojo memiliki potensi untuk melestarikan karawitan. Namun kendala yang ada adalah PAUD di Karangmojo belum memiliki seperangkat gamelan kecil untuk anak-anak, sehingga belum bisa mengajarkan ilmu ini ke anak-anak,

Kegiatan pelatihan dan pementasan wayang uwong Pathok tunggorono yang dilakukan di Joglo Sokoliman berlangsung dengan lancar tanpa kendala berkat keseriusan para pemain wayang uwong dan pemain gamelan dalam berlatih maupun saat pementasan berlangsung, serta berkat dukungan warga sekitar dalam persiapan acara pementasan wayang uwong. Pementasan wayang uwong bertujuan untuk memberikan kegiatan kepada karang taruna berbasis budaya, serta menjalin kerjasama antara karang taruna Sokoliman dengan Universitas Negeri Yogyakarta.

\section{DAFTAR PUSTAKA}

Adler, P.A. \& Adler, P. (2009). "Teknik-teknik Observasi” dalam Denzin, K. Norman \& Lincoln, Y.S. (2009). Handbook of Qualitative Research. Yogyakarta: Pustaka Pelajar.

Ariesty Fujiastuti, (t.t.) Penanaman pendidikan karakter melalui budaya jawa (ketoprak). Retrieved from http://journal.uad.ac.id/index.php/BAHASTRA/article/view/3970.

Creswell, J.W. (2008). Educational research, planning, conducting, and evaluating quantitative and qualitative research. Third Edition. New Jersey: Pearson Education Merrill Prentice Hall.

Deony Dewanggi Mulyono. (t.t.). Kampanye penanaman cinta budaya jawa pada remaja melalui pagelaran wayang orang sriwedari. Retrieved from https://openlibrary. telkomuniversity.ac.id/pustaka/145692/kampanye-penanaman-cinta-budaya-jawa-padaremaja-melalui-pagelaran-wayang-orang-sriwedari.html

Erni Munastiwi. (2015), Implementasi pendekatan saintifik pada pembelajaran pendidikan anak usia dini (PAUD). retrieved 30 Agustus 2019 from http://ejournal.uinsuka.ac.id/tarbiyah/ index.php/alathfal/article/ view/1087/992

Fontana, A. \& Frey, J.H. (2009). "Wawancara Seni Ilmu Pengetahuan" dalam Denzin, K. Norman \& Lincoln, Y.S. (2009). Handbook of Qualitative Research. Yogyakarta: Pustaka Pelajar.

Gronlund, G. \& Engel, B. (2001). Focused portfolios: A complete assessment for the young child. St. Paul, MN: Readleaf Press.

Hartono. (2012). Perkembangan estetika musikal seni karawitan jawa dan pengaruhnya terhadap masyarakat pendukungnya. Jurusan Seni dan Desain Fakultas Sastra Universitas Negeri Malang. Retrieved from http://jurnalonline.um.ac.id/data/artikel/artikel6483F7762BD642DEA913F3F56FD103B4.pdf

Hodder, I. (2009). "Interpretasi dokumen dan kebudayaan mateial" dalam Denzin, K. Norman \& Lincoln, Y.S. (2009). Handbook of Qualitative Research. Yogyakarta: Pustaka Pelajar.

Lincoln, Y.S. \& Guba, E.G. (1985). Naturalistic Inquiry. Beverly Hills, CA: Sage.

Morris, W. (Ed.). (1973). The american heritage dictionary of the english language. Boston: Houghton Mifflin.

Nilsen, B.A. (2004). Week by week: Documenting the development of young children. Australia: Thomson Delmar Learning.

Richard, C.M., Maxwell, L.K. (2004). School readness assessment. YC Yaung Children, Woshington: Jan. Vol.59, Iss. 1 pg. 42, 5 pgs. Retrieved tgl 5 Agustus 2006 from http://www.proquest. umi.com/pqdweb. 